\title{
Homocoupling of Terminal Alkynes Catalysed by Ultrafine Copper Nanoparticles on Titania
}

\author{
Francisco Alonso, ${ }^{*[a]}$ Taki Melkonian, ${ }^{[a][* 1}$ Yanina Moglie, ${ }^{[a]}$ and Miguel Yus ${ }^{*[a]}$
}

\author{
Dedicated to Professor Georgi N. Andreev on the occasion of his 70th birthday
}

Keywords: Alkynes / C-C coupling / Copper / Nanoparticles / Titanium / Heterogeneous catalysis

Copper nanoparticles on titania effectively catalyse the oxidative homocoupling of terminal alkynes in the presence of piperidine as a base in tetrahydrofuran (THF) or under solvent-free conditions. A wide range of diynes have been synthesised in high yields using low catalyst loading (1 mol-\%
$\mathrm{Cu}$ ). The copper catalyst (mainly as $\mathrm{Cu}_{2} \mathrm{O}$ ) has been characterised by different means, is easy to prepare, can be reutilised several times, works either in air or under inert atmosphere and was shown to be superior to other commercially available copper sources.

\section{Introduction}

Conjugated 1,3-diynes are structural moieties often found in natural products with prominent biological activities, such as antibacterial, antimicrobial, antifungal, antitumor, anticancer, anti-HIV, and pesticidal agents. ${ }^{[1]}$ This unit plays an important role in molecular recognition (e.g., molecular boxes) as well as in the design of advanced materials such as conjugated polymers, liquid crystals, molecular wires, or non-linear optic materials, amongst others. ${ }^{[2]}$

Although 1,3-diynes can be obtained by homocoupling of various alkynyl organometallics, the homocoupling of terminal alkynes can be considered to be the most direct route to these types of compounds. ${ }^{[3]}$ In this respect, the oxidative dimerisation of copper(I) acetylides, discovered in 1869 by Glaser, ${ }^{[4]}$ has recently experienced an intense revival, which has led to an array of methods involving catalytic amounts of copper salts. ${ }^{[3,5]}$ To maximize the general efficiency of the process, however, efforts must be focused on developing catalytic systems that are simple (e.g., operate without palladium and additives such as oxidants or ligands), environmentally friendly (e.g., green solvents or solvent-free), minimise the amount of copper, and are recyclable. In this latter sense, heterogeneous catalysts are advantageous over their homogeneous counterparts, offering easy recovery and recycling as well as enhanced stability. ${ }^{[6]}$

[a] Departamento de Química Orgánica, Facultad de Ciencias and Instituto de Síntesis Orgánica (ISO), Universidad de Alicante, Apdo. 99, 03080 Alicante, Spain

Fax: +34-965903549

E-mail: falonso@ua.es yus@ua.es

[\$] Visiting Erasmus student at the University of Alicante, February through May 2010. On leave from the University of Plovdiv (Bulgaria)
The heterogeneous copper-catalysed homocoupling of terminal alkynes has also been a subject of recent interest but have rarely been studied. For instance, a CuAl hydrotalcite exhibited excellent recyclability at room temperature in acetonitrile, although stoichiometric amounts of $N, N, N^{\prime}, N^{\prime}$ tetramethylethylenediamine (TMEDA) and catalyst (110 mol-\%) were required. ${ }^{[7]}$ Copper(I) zeolites were tested for the title reaction in $N, N$-dimethylformamide (DMF) at $110^{\circ} \mathrm{C}$ and $30 \mathrm{~mol}-\%$ copper loading, with no apparent possibility of catalyst recycling. ${ }^{[8]}$ Mizuno and co-workers reported a catalyst consisting of $\mathrm{Cu}(\mathrm{OH})_{x} / \mathrm{TiO}_{2}(5 \mathrm{~mol}-\%$ $\mathrm{Cu}$ ) that did not require the presence of a base and showed high catalytic activity in toluene at $100{ }^{\circ} \mathrm{C}$ under $1 \mathrm{~atm}$ $\mathrm{O}_{2} \cdot{ }^{[9]}$ Only one recycling experiment was described in this article, which showed a slight decrease in yield (from 90 to $82 \%$ ). Finally, copper(0) nanoparticles were also found to promote this homocoupling in tetrahydrofuran (THF) at reflux, either in the absence $(400 \mathrm{~mol}-\% \mathrm{Cu})$ or presence of $\mathrm{Na}_{2} \mathrm{CO}_{3}(50 \mathrm{~mol}-\% \mathrm{Cu}) .{ }^{[10]}$ The copper nanoparticles were not recovered and, because half of the required amount of reductant for $\mathrm{CuCl}_{2}$ was employed, doubts remain as to whether $\mathrm{Cu}^{0}$ or some other species were the true catalyst.

As part of our study on the reactivity of active metals, ${ }^{[11]}$ we discovered that the system composed of copper(II) chloride dihydrate $\left(\mathrm{CuCl}_{2} \cdot 2 \mathrm{H}_{2} \mathrm{O}\right)$, lithium metal, and a catalytic amount of 4,4'-di-tert-butylbiphenyl (DTBB) in THF, generates active copper that is applicable to the reduction of a range of different organic functionalities. ${ }^{[12]}$ Subsequently, we observed that copper nanoparticles (CuNPs) are formed under the above mentioned conditions when either copper(II) chloride dihydrate or anhydrous copper(II) chloride were used. In the latter case, the unsupported CuNPs were found to effectively catalyse the 1,3-dipolar cycloaddition 
of azides and terminal alkynes in short reaction times and in the absence of any stabilising additive or ligand. ${ }^{[13]}$ More recently, $\mathrm{CuNPs} / \mathrm{C}$ were found to perform well in a multicomponent synthesis of 1,2,3-triazoles in water. ${ }^{[14]}$ Trying to expand the application of nanoparticles in organic chemistry, we wish to present herein our results on the heterogeneous homocoupling of terminal alkynes catalysed by supported CuNPs.

\section{Results and Discussion}

A variety of copper catalysts were prepared by addition of the support to a suspension of recently prepared CuNPs. The latter were readily generated from anhydrous copper(II) chloride, lithium metal, and a catalytic amount of DTBB $(10 \mathrm{~mol}-\%)$ in THF at room temperature. The supported catalysts were not subjected to any treatment prior to use. A first screening was conducted to optimise the catalyst support, using approximately $5 \mathrm{~mol}-\% \mathrm{Cu}$ and the homocoupling of phenylacetylene as a model reaction in refluxing THF (Table 1). Activated carbon, which was shown to be an ideal support for the multicomponent synthesis of 1,2,3-triazoles in water, ${ }^{[14]}$ only gave a moderate yield with TMEDA as a base, with some other bases yielding less than $20 \%$ of $\mathbf{2 a}$ (Table 1, entries $1-8$ ). $\mathrm{KOH}$ was not an appropriate base for zeolite $\mathrm{Y}, \mathrm{MgO}, \mathrm{Al}_{2} \mathrm{O}_{3}$ or magnetite (Table 1, entries 9-12), but piperidine led to the homocoupled product in moderate or high yield with $\mathrm{Al}_{2} \mathrm{O}_{3}$ or magnetite, respectively (Table 1 , entries 15 and 16). The combination of $\mathrm{TiO}_{2}$ as support and piperidine as a base furnished the expected diyne quantitatively in much shorter time than other combinations (Table 1, entry 17). This result could not be improved by the use of magnetite in the presence of other bases (Table 1, entries 18-20).

A variety of bases and solvents were tested in a second screening focused on the catalyst composed of copper nanoparticles on titania (Table 2). Low conversion was observed for the reaction with piperidine conducted at room temperature in THF (Table 2, compare entries 1 and 2). A higher yield of 2a was achieved with pyridine as base when compared with TMEDA and $\mathrm{Et}_{3} \mathrm{~N}$, although a longer reaction time was needed than with piperidine (Table 2, entries $3-5)$. Solvents other than THF were found to be very inefficient for the alkyne homocoupling (Table 2, entries 6-12). It is worth noting that both the catalyst loading and amount of piperidine could be decreased to $1 \mathrm{~mol}-\%$ and $30 \mathrm{~mol}-\%$, respectively, while maintaining excellent performance (Table 2, entries 13-16). Moreover, the process was equally effective but faster under solvent-free conditions (Table 2, entry 17).

The $\mathrm{CuNPs} / \mathrm{TiO}_{2}$ catalyst was characterised by different means, including transmission electron microscopy (TEM), $\mathrm{X}$-ray photoelectron spectroscopy (XPS), and powder Xray diffraction (XRD), amongst others. A copper content of 3.0 wt. $-\%$ in the catalyst was determined by inductively coupled plasma mass spectrometry (ICP-MS). Analysis by TEM revealed the presence of well-defined and dispersed
Table 1. Optimisation of the support. ${ }^{[a]}$

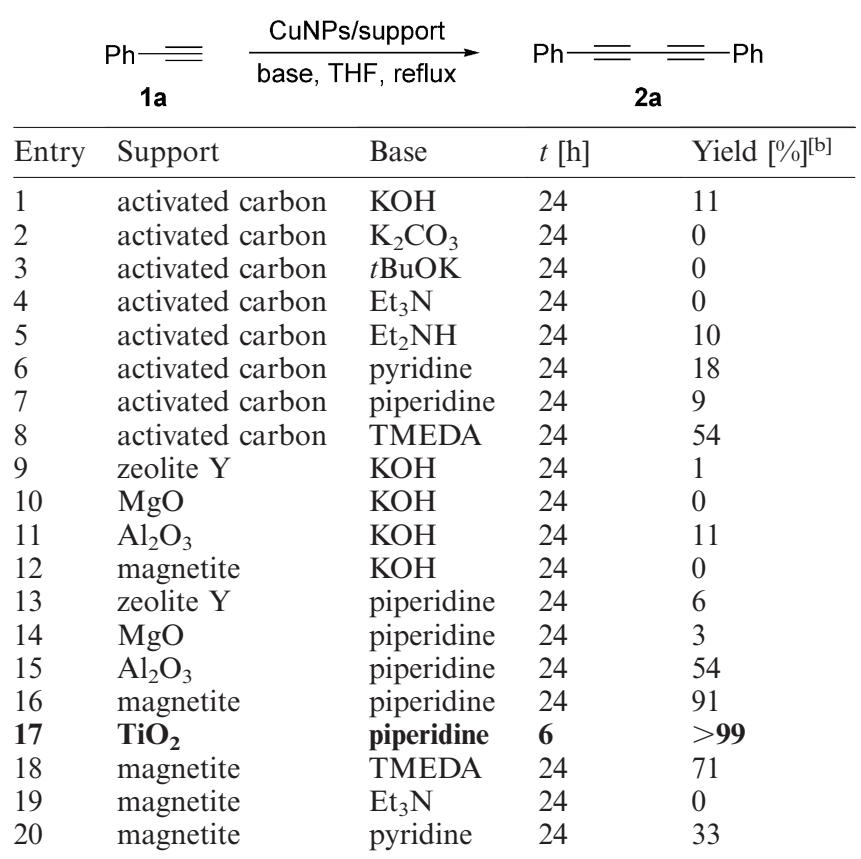

[a] Reagents and conditions: 1a $(1 \mathrm{mmol})$, base $(1 \mathrm{mmol}), \mathrm{CuNPs} /$ support (ca. 5 mol- $\% \mathrm{Cu}$ ) in THF at reflux, $24 \mathrm{~h}$. [b] GC yield.

Table 2. Optimisation of the reaction conditions. ${ }^{[\mathrm{a}]}$

\begin{tabular}{|c|c|c|c|c|c|}
\hline & $\mathrm{Ph} \overline{\overline{1 a}}$ & $\frac{\mathrm{CuNPs} / \mathrm{TiO}_{2}}{\text { base, solvent, } 65^{\circ} \mathrm{C}}$ & $\mathrm{Ph}=$ & $\overline{2 a}$ & \\
\hline Entry & $\begin{array}{l}\text { Catalyst } \\
{[\mathrm{mol}-\%]}\end{array}$ & Base $[\mathrm{mol}-\%]$ & Solvent & $t[\mathrm{~h}]$ & $\begin{array}{l}\text { Yield } \\
{[\%]^{[b]}}\end{array}$ \\
\hline 1 & 5 & piperidine [100] & THF & 6 & $>99$ \\
\hline 2 & 5 & piperidine [100] & $\mathrm{THF}$ & $24^{[\mathrm{c}]}$ & 22 \\
\hline 3 & 5 & TMEDA [100] & THF & 24 & 50 \\
\hline 4 & 5 & $\mathrm{Et}_{3} \mathrm{~N}[100]$ & $\mathrm{THF}$ & 24 & 0 \\
\hline 5 & 5 & pyridine [100] & $\mathrm{THF}$ & 24 & 93 \\
\hline 6 & 5 & piperidine [100] & $\mathrm{H}_{2} \mathrm{O}$ & 24 & 4 \\
\hline 7 & 5 & $\mathrm{Na}_{2} \mathrm{CO}_{3}[100]$ & $\mathrm{H}_{2} \mathrm{O}$ & 24 & 4 \\
\hline 8 & 5 & piperidine [100] & toluene & 24 & 0 \\
\hline 9 & 5 & piperidine [100] & $\mathrm{MeCN}$ & 24 & 0 \\
\hline 10 & 5 & piperidine [100] & $\mathrm{EtOH}$ & 24 & 0 \\
\hline 11 & 5 & piperidine [100] & DMSO & 24 & 0 \\
\hline 12 & 5 & piperidine [100] & acetone & 24 & 0 \\
\hline 13 & 2.5 & piperidine [100] & THF & 6 & 95 \\
\hline 14 & 1 & piperidine [100] & THF & 6 & $>99$ \\
\hline 15 & 1 & piperidine [30] & THF & 6 & $>99$ \\
\hline 16 & 1 & piperidine $[10]$ & $\mathrm{THF}$ & 10 & 80 \\
\hline 17 & 1 & piperidine $[30]$ & - & 3 & $>99$ \\
\hline
\end{tabular}

[a] Reagents and conditions: 1a (1 mmol), base, $\mathrm{CuNPs} / \mathrm{TiO}_{2}$, solvent, $65^{\circ} \mathrm{C}$. [b] GC yield. [c] Reaction performed at room temperature.

spherical nanoparticles on the titania with diameters of approximately $1.0 \pm 0.4 \mathrm{~nm}$ (Figure 1). We were delighted with the astonishing ultrafine size and narrow distribution obtained for the supported nanoparticles, because the chemical reduction methods usually furnish nanoparticles of sizes in the range of $10-50 \mathrm{~nm}$. To the best of our knowledge, only two recent procedures achieve comparable sizes to 
those reported herein. CuNPs of $1.4 \pm 0.6 \mathrm{~nm}$ were fabricated by a modified polyol method involving poly $(N$-vinylpirrolidone) and sodium borohydride in alkaline ethylene glycol. ${ }^{[15]}$ The reduction of aqueous $\mathrm{Cu}^{\mathrm{II}}$ by sodium citrate, in the presence of $N, N, N^{\prime}, N^{\prime}$-tetramethyl-p-phenylenediamine and hydrophobically immobilised sodium dodecylbenzenesulfonate, produced CuNPs of approximately $2 \mathrm{~nm} .{ }^{[16]}$
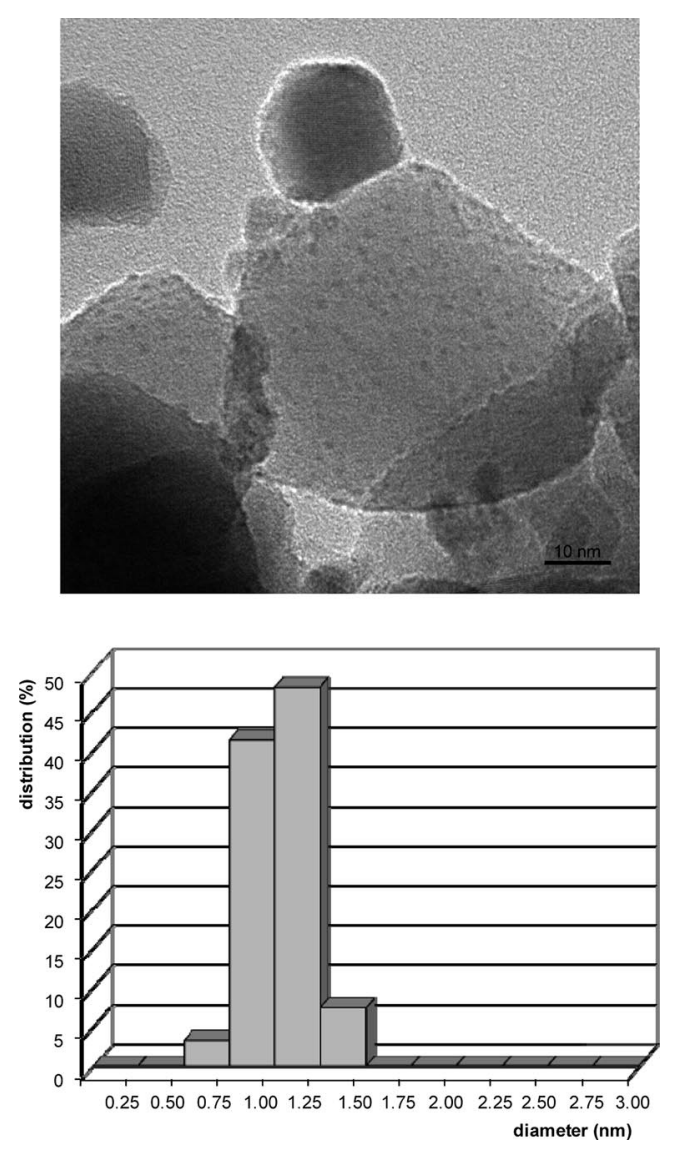

Figure 1. TEM micrograph and size distribution of the CuNPs/ $\mathrm{TiO}_{2}$ catalyst. The sizes were determined for 125 nanoparticles selected at random.

Energy-dispersive X-ray (EDX) analysis on various areas confirmed the presence of copper on the support, with energy bands of 8.04, 8.90 ( $K$ lines) and $0.92 \mathrm{keV}(L$ line) (Figure 2). The XRD diffractogram did not show any significant peak for copper due to the small crystal domains and/ or low copper loading weight. ${ }^{[17]}$ The XPS spectrum dis- plays a single $\mathrm{Cu} 2 \mathrm{p}_{3 / 2}$ peak at $932.7 \mathrm{eV}$ (Figure 3). Because neither a significant shoulder peak at $934.0 \mathrm{eV}$ nor the satellite shakeup feature characteristic of $\mathrm{Cu}^{\mathrm{II}}$ species were observed, the presence of $\mathrm{CuO}$ can be discarded. It is, however, difficult to differentiate between $\mathrm{Cu}^{0}$ and $\mathrm{Cu}^{\mathrm{I}}$ on the basis of only XPS studies due to the close proximity of the their binding energies (ca. 932.0-933.0 eV). ${ }^{[18]}$ According to our experience, ${ }^{[13,14]}$ the possibility of having $\mathrm{Cu}^{0}$ nanoparticles is rather low because the catalyst was handled under air. The Auger analysis can complement the data obtained from XPS, where the kinetic energies for $\mathrm{Cu}, \mathrm{Cu}_{2} \mathrm{O}$ and $\mathrm{CuO}$ are $918.2,916.0$ and $917.6 \mathrm{eV}$, respectively. ${ }^{[19]} \mathrm{In}$ our case, the Auger spectrum denotes primarily the presence of $\mathrm{Cu}_{2} \mathrm{O}$ (Figure 4), which is in agreement with the aforementioned data.

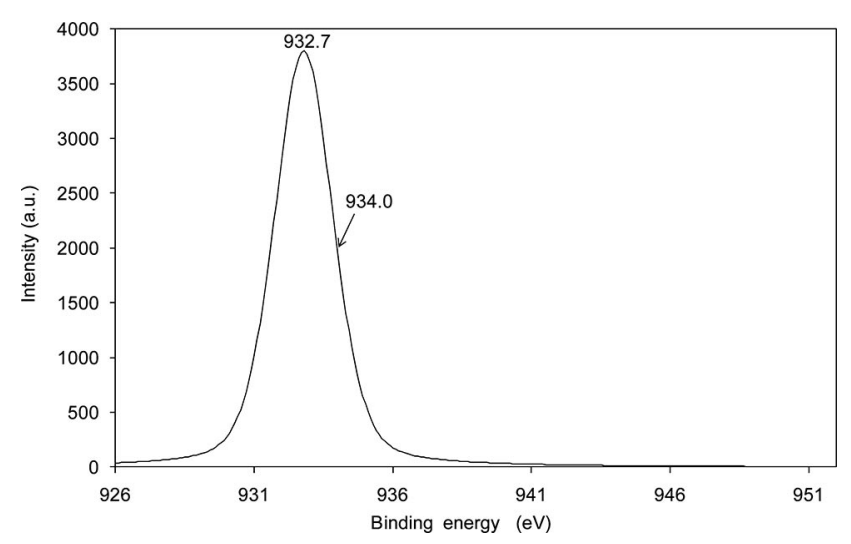

Figure 3. XPS spectrum of $\mathrm{CuNPs} / \mathrm{TiO}_{2}$.

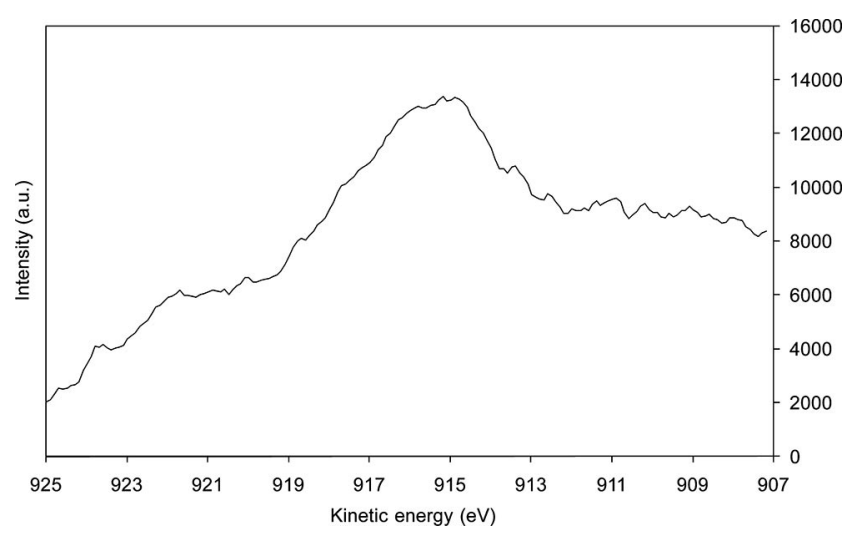

Figure 4. Auger spectrum of $\mathrm{CuNPs} / \mathrm{TiO}_{2}$.

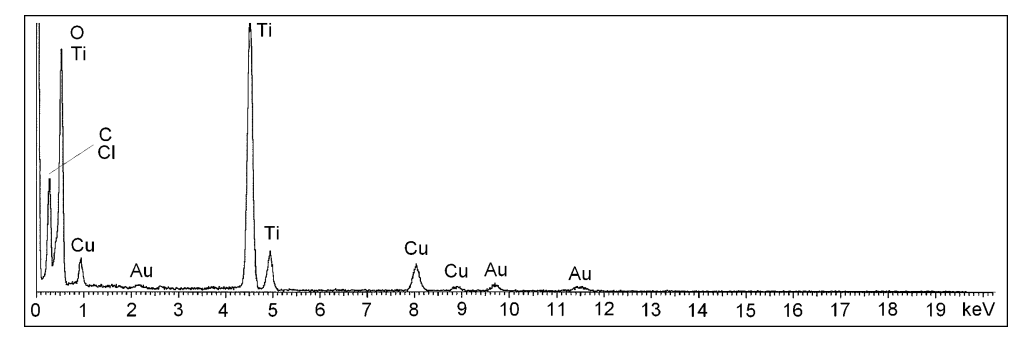

Figure 2. EDX spectrum of the CuNPs obtained from a selected area. 
With an optimised catalyst and reactions conditions in hand (Scheme 1), we explored the homocoupling of a wide range of terminal alkynes (Table 3). For comparative purposes, the reactions in THF and under solvent-free conditions were both studied. A range of substituted aryl-acetylenes were first tested to determine possible electronic effects. Phenyl acetylene (1a) and 4-methylphenylacetylene (1b) gave the corresponding homocoupled products in excellent yields irrespective of the solvent conditions. The reaction time was, however, considerably shorter in the absence of solvent (Table 3, entries 1 and 2). The trifluoromethyl-substituted diyne $\mathbf{2 c}$ was obtained faster and in higher yield without solvent (Table 3, entry 3 ). In contrast, 2-aminophenylacetylene (1d) could not be dimerised under the latter conditions, although the reaction in THF took place smoothly (Table 3, entry 4). The presence of an electrondonating group at the 4-position of the aryl ring (as for the methoxy-substituted derivative 1e) reduced the reactivity of the acetylene, probably because the corresponding acetylide was more difficult to form (Table 3 , entry 5 ). The reaction conditions were compatible with heterocyclic substrates, such as 2-ethynylpyridine (1f), although the use of piperidine as a base was mandatory for the reaction to occur (Table 3, entry 6). Linear, branched and cyclic alkyl-substituted acetylenes $(\mathbf{1 g}-\mathbf{j})$, as well as the enyne 1-ethynylcyclohex-1-ene (1k) furnished the expected diynes $2 \mathbf{g}-\mathbf{k}$ in good-to-excellent yields (Table 3, entries 7-11). In all these examples, the reaction times were notably decreased in the solvent-free version (14-16 h vs. 2-5 h). We next applied the methodology to some functionalised substrates. For instance, 6-chlorohex-1-yne (11) and hept-6-ynenitrile (1m) afforded $\mathbf{2} \mathbf{l}$ and $\mathbf{2 m}$, respectively, in similar yields, independent of the method used (Table 3, entries 12 and 13). The reaction time for 11 was, however, substantially shortened in the solvent-free approach. No difference in the reaction time was observed for the propargyl oxygenated alkynes $\mathbf{1 n}$ and 1o, although higher yields were achieved in THF (Table 3, entries 14 and 15). Finally, (trimethylsilyl)acetylene (1p) was readily transformed into the corresponding buta-1,3-diyne $2 p$ regardless of the solvent conditions.

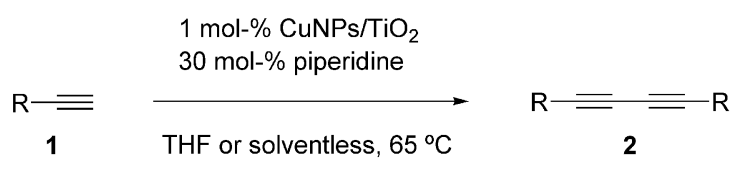

Scheme 1. Optimised catalyst and reaction conditions.

To better assess the efficiency of the $\mathrm{CuNPs} / \mathrm{TiO}_{2}$ catalyst, we undertook a comparative study with some commercially available catalysts under the aforementioned optimised conditions (Table 4). Copper metal and copper(I) oxide at 10 mol- $\%$ gave very poor conversions, whereas with copper(II) oxide the starting material was recovered untouched (Table 4, entries 1-3). Relatively good conversions were achieved with the copper(I) and copper(II) chlorides also at $10 \mathrm{~mol}-\%$ after prolonged heating. The reaction could not be completed, however, in the case of $\mathrm{CuCl}$, and several by-products were detected with $\mathrm{CuCl}_{2}$ (Table 4, en- tries 4 and 5). The conversions dramatically dropped when the catalyst loading was reduced to $1 \mathrm{~mol}-\%$, both for $\mathrm{CuCl}$ and $\mathrm{CuCl}_{2}$ (Table 4, entries 6 and 7). Therefore, we can conclude that the $\mathrm{CuNPs} / \mathrm{TiO}_{2}$ catalyst system is much superior to commercially available alternatives with respect to catalyst loading, reaction time and conversion (Table 4, entry 8).

The catalyst could be easily recovered by filtration and reused without any pre-treatment. Conversions of $>99,92$ and $89 \%$ were recorded in the homocoupling of phenylacetylene along three consecutive runs. To test the robustness of the catalyst and unveil the nature of the catalysis, the reaction of phenylacetylene was run up to $65 \%$ conversion. At this point the catalyst was filtered off and the resulting THF solution was allowed to react under reflux for $14 \mathrm{~h}$. A slight increase in the conversion (ca. 70\%) was observed. The aqueous phase obtained after work-up was submitted to ICP-MS analyses, which showed the presence of $45 \mathrm{ppb}$ of copper. These results point to a process of heterogeneous nature.

We must underline that all reactions in Table 3 were performed in reactor tubes without the exclusion of air and without the need for an oxygen atmosphere, which made the method operationally simple. Nonetheless, we decided to investigate the possible effect of different types of atmospheres on the outcome of the reaction (Table 5). High conversion was obtained when the reaction was carried out in THF with a flask equipped with a condenser open to air (Table 5, entry 2). It was quite surprising to find that moderate conversion was achieved using anhydrous THF under $\operatorname{Ar}$ (Table 5, entries 3 and 4), and complete conversion without solvent under Ar after prolonged heating (Table 5, entries 5 and 6). A noticeable effect of oxygen regarding the reaction time and conversion was observed both in THF and under solvent-free conditions (Table 5, entries 7 and 8). Interestingly, moderate conversions were also recorded under an inert atmosphere with the commercial copper chlorides, either separately or mixed (compare entries 9-12 in Table 5 with entries 4 and 5 in Table 4). To remove any trace of oxygen from the reaction flask, the reactions under Ar were subjected to 20 vacuum-Ar refilling cycles in the presence of the catalyst prior to the addition of the reagents and solvent. A deviation of up to $20 \%$ conversion (with respect to the standard 3-fold vacuum-Ar refilling cycles) was observed for entries 3-5 (Table 5), whereas no appreciable variation was detected in entries 6, 9 and 10 (Table 5). Substantial release of oxygen from the catalyst was manifested only between $250-300{ }^{\circ} \mathrm{C}$ by temperature-programmed desorption (TPD), which practically rules out its participation in the catalytic cycle. The above results are in clear contrast to those recently reported by Mizuno et al., in which, under an $\mathrm{Ar}$ atmosphere, phenylacetylene was converted into $2 \mathrm{a}$ in only approximately $2 \%$ conversion. ${ }^{[9]}$ The presence of an oxidising agent [e.g., air, $\mathrm{O}_{2}, \mathrm{I}_{2}, N$-bromosuccinimide (NBS), etc.] is a common feature in the homocoupling of alkynes promoted by copper. However, Clifford and Waters showed in 1963 that the reaction could be accomplished in the absence of oxygen when $\mathrm{Cu}^{\mathrm{I}}$ ions 
Table 3. Homocoupling of terminal alkynes catalysed by $\mathrm{CuNPs} / \mathrm{TiO}_{2}{ }^{\left[{ }^{[a]}\right.}$

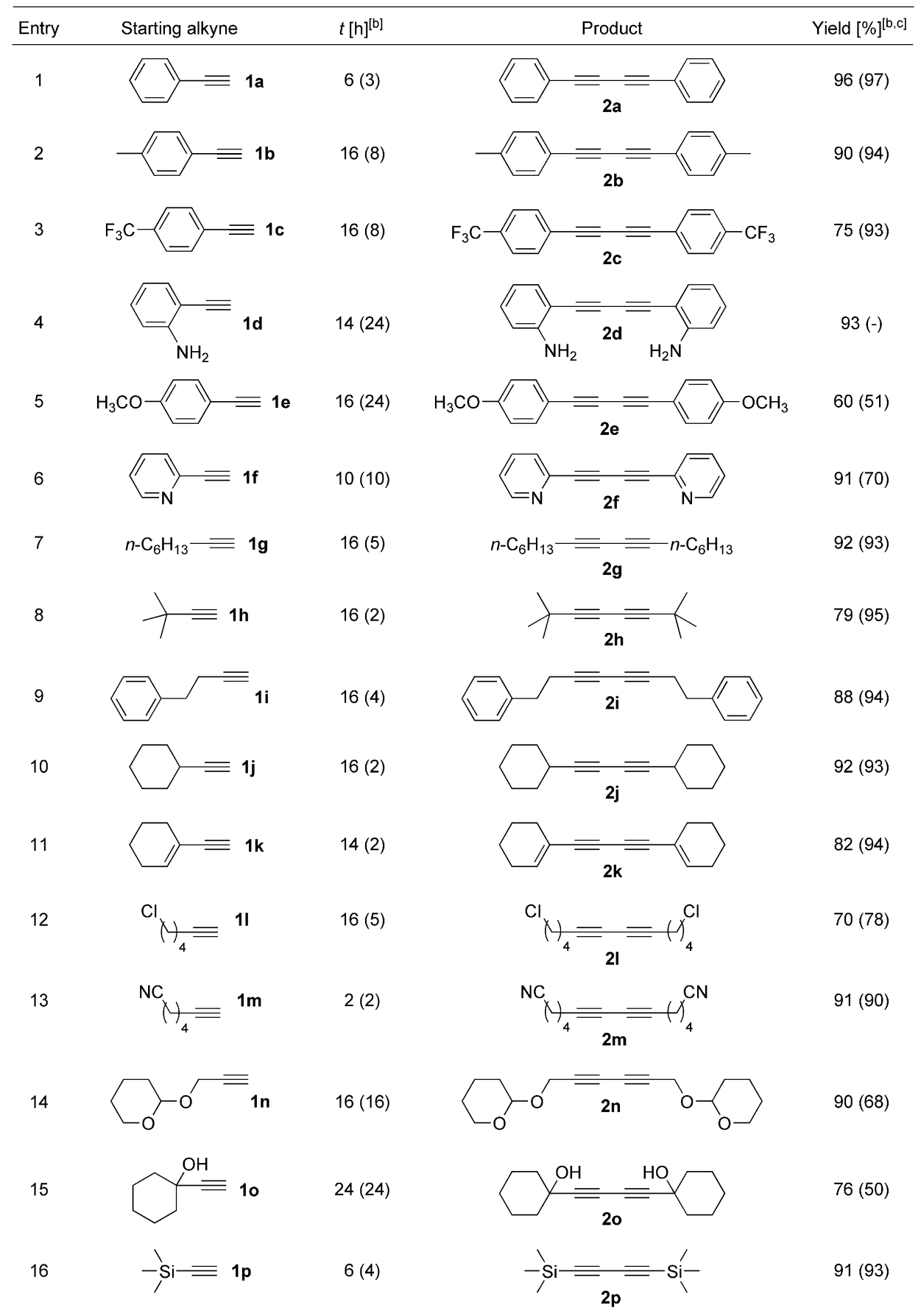

[a] Reaction conditions: 1 (1 mmol), $\mathrm{CuNPs} / \mathrm{TiO}_{2}(1 \mathrm{~mol}-\%)$, piperidine $(30 \mathrm{~mol}-\%)$ in $\mathrm{THF}$ or solventless at $65^{\circ} \mathrm{C}$. [b] Isolated yield. [c] Data corresponding to the solvent-free reaction in parenthesis.

were combined with $\mathrm{Cu}(\mathrm{OAc})_{2}$ in pyridine. ${ }^{[20]}$ We have demonstrated that the presence of air or oxygen increases the homocoupling rate, but they are not required to attain moderate conversions with the copper chlorides and moderate-to-excellent conversions with $\mathrm{CuNPs} / \mathrm{TiO}_{2}$. The addition of radical traps, such as norbornene, cumene, 2,2,6,6tetramethylpiperidine-1-oxyl (TEMPO) or 2,6-di-tert-butylphenol, did not inhibit the standard reaction catalysed by $\mathrm{CuNPs} / \mathrm{TiO}_{2}$ and no products derived from their reaction with alkynyl radicals were detected. As asserted by Diederich and co-workers, ${ }^{[3 a]}$ it is admitted that the mechanism of the copper-catalysed oxidative alkyne homocoupling is rather complex and that its current understanding remains unsatisfactory. Further research on new catalytic systems and the role of their components will, therefore, be welcome. 
Table 4. Homocoupling of phenylacetylene with different copper catalysts. ${ }^{[a]}$

\begin{tabular}{|c|c|c|c|c|}
\hline \multicolumn{2}{|c|}{$\mathrm{Ph}=$} & $\overrightarrow{\text { piperidine, } T H F, \text { reflux }}$ & \multicolumn{2}{|c|}{$\mathrm{Ph}=\overline{\mathbf{2 a}_{\mathbf{a}}} \overline{\overline{ }} \mathrm{Ph}$} \\
\hline Entry & $\mathrm{Cu}$ & atalyst [mol- $\%$ ] & $t[\mathrm{~h}]$ & Conversion $[\%]^{[b]}$ \\
\hline 1 & $\mathrm{Cu}$ & & 16 & 6 \\
\hline 2 & $\mathrm{Cu}_{2}$ & [10] & 16 & 9 \\
\hline 3 & $\mathrm{CuC}$ & [10] & 16 & 0 \\
\hline 4 & $\mathrm{CuC}$ & {$[10]$} & 24 & 74 \\
\hline 5 & $\mathrm{CuC}$ & $2[10]$ & 16 & $80^{[\mathrm{c}]}$ \\
\hline 6 & $\mathrm{CuC}$ & {$[1]$} & 24 & 4 \\
\hline 7 & $\mathrm{CuC}$ & $2[1]$ & 24 & 4 \\
\hline 8 & $\mathrm{CuN}$ & $\mathrm{Ps} / \mathrm{TiO}_{2}[1]$ & $6(3)^{[\mathrm{d}]}$ & $>99$ \\
\hline
\end{tabular}

[a] Reagents and conditions: 1a $(1 \mathrm{mmol})$, piperidine $(30 \mathrm{~mol}-\%)$, $\mathrm{Cu}$ catalyst, THF, reflux. [b] Determined by GC. [c] Several byproducts were observed. [d] Solvent-free reaction time in parenthesis.

Table 5. Effect of the atmosphere on the homocoupling of phenylacetylene. ${ }^{[a]}$

\begin{tabular}{|c|c|c|c|c|c|}
\hline \multicolumn{2}{|r|}{$\mathrm{Ph} \underset{1 \mathrm{a}}{\bar{\equiv}}$} & $\frac{\text { Cu cata }}{\text { piperidine }}$ & $\frac{\text { yst }}{65^{\circ} \mathrm{C}}$ & $\overline{2 a}$ & $=-\mathrm{Ph}$ \\
\hline Entry & $\mathrm{Cu}$ cataly & st [mol-\%] & Conditions & $t[\mathrm{~h}]$ & $\begin{array}{l}\text { Conversion } \\
{[\%]^{[b]}}\end{array}$ \\
\hline 1 & $\mathrm{CuNPs} / \mathrm{T}$ & $\mathrm{O}_{2}[1]$ & $\mathrm{THF}^{[\mathrm{c}]}$ & 6 & $>99$ \\
\hline 2 & $\mathrm{CuNPs} / \mathrm{T}$ & $\mathrm{O}_{2}[1]$ & THF, air ${ }^{[\mathrm{d}]}$ & 6 & 95 \\
\hline 3 & CuNPs/T & $\mathrm{O}_{2}[1]$ & dry THF, Ar & 6 & $50(30)$ \\
\hline 4 & CuNPs/T & $\mathrm{O}_{2}[1]$ & dry THF, Ar & 24 & $58(40)$ \\
\hline 5 & $\mathrm{CuNPs} / \mathrm{T}$ & $\mathrm{O}_{2}[1]$ & no solvent, $\mathrm{Ar}$ & 6 & $71(50)$ \\
\hline 6 & $\mathrm{CuNPs} / \mathrm{T}$ & $\mathrm{iO}_{2}[1]$ & no solvent, $\mathrm{Ar}$ & 24 & $>99$ (94) \\
\hline 7 & CuNPs/T & $\mathrm{iO}_{2}[1]$ & $\mathrm{THF}, \mathrm{O}_{2}{ }^{[\mathrm{e}]}$ & 4 & $>99$ \\
\hline 8 & $\mathrm{CuNPs} / \mathrm{T}$ & $\mathrm{O}_{2}[1]$ & no solvent, $\mathrm{O}_{2}{ }^{[\mathrm{e}]}$ & 0.5 & $>99$ \\
\hline 9 & $\mathrm{CuCl}[10$ & & dry THF, Ar & 24 & $70(66)$ \\
\hline 10 & $\mathrm{CuCl}_{2}[1$ & & dry THF, Ar & 24 & $58(61)$ \\
\hline 11 & $\mathrm{CuCl}[10$ & $\mathrm{CuCl}_{2}[10]$ & dry THF, Ar & 2 & 55 \\
\hline 12 & $\mathrm{CuCl}[10$ & $\mathrm{CuCl}_{2}[10]$ & dry THF, Ar & 16 & 68 \\
\hline
\end{tabular}

[a] Reagents and conditions: 1a $(1 \mathrm{mmol})$, piperidine $(30 \mathrm{~mol}-\%)$, $\mathrm{Cu}$ catalyst, $65^{\circ} \mathrm{C}$ in reactor tube. [b] Determined by GC. Values in parenthesis correspond to 20 vacuum-Ar refilling cycles (instead of the standard 3 cycles) in the presence of the catalyst prior to addition of the reagents and solvent. [c] Non-dried THF was used unless otherwise stated. [d] Reaction performed in a flask with the condenser open to air. [e] Reaction performed under $1 \mathrm{~atm} \mathrm{O}_{2}$.

\section{Conclusions}

Supported copper nanoparticles have been shown for the first time to promote the homocoupling of terminal alkynes. The catalyst composed of ultrafine $\mathrm{CuNPs} / \mathrm{TiO}_{2}$ exhibits the best performance both in THF and without any solvent, giving the corresponding 1,3-diynes in high yields. A full characterisation of the catalyst allowed to conclude that the copper nanoparticles are mainly oxidised in the form of $\mathrm{Cu}_{2} \mathrm{O}$. This catalyst was found to be much more efficient than other commercially available catalysts based on copper. Moreover, the catalyst, with low metal loading, can be reused several times with negligible leaching. Apparently, no alkynyl radicals are involved in the process, which is operationally simple (an oxygen atmosphere is not re- quired) and which, astonishingly, can also provide high yields of product in an inert atmosphere.

\section{Experimental Section}

General: Anhydrous copper(II) chloride (Aldrich), lithium powder (MEDALCHEMY S. L.), and DTBB (Aldrich) were commercially available. Degussa $\mathrm{P} 25 \mathrm{TiO}_{2}(60 \%$ anatase, $40 \%$ rutile $)$ with a surface area of $50 \mathrm{~m}^{2} \mathrm{~g}^{-1}$ was used as support, after being calcined in air at $500{ }^{\circ} \mathrm{C}$ for $5 \mathrm{~h}$. All the starting materials and other reagents were of the best grade commercially available (Aldrich, Acros, Alfa Aesar, Panreac) and were used without further purification. THF was dried in a Sharlab PS-400-3MD solvent purification system using an alumina column. All reactions were carried out with a multireactor apparatus using the corresponding reactor tubes. The purity of volatile compounds and the chromatographic analyses (GC) were determined with a Hewlett-Packard HP-6890 instrument equipped with a flame ionization detector and a $30 \mathrm{~m}$ capillary column ( $0.32 \mathrm{~mm}$ diameter, $0.25 \mu \mathrm{m}$ film thickness), using nitrogen $(2 \mathrm{~mL} / \mathrm{min})$ as carrier gas; $T_{\text {injector }}=275^{\circ} \mathrm{C}, T_{\text {column }}=60^{\circ} \mathrm{C}$ (3 min) and $60-270{ }^{\circ} \mathrm{C}\left(15^{\circ} \mathrm{C} / \mathrm{min}\right)$. Column chromatography was performed using silica gel 60 of 40-60 microns (hexane/EtOAc as eluent).

The TEM image was recorded using a JEOLJEM2010 microscope, equipped with a lanthanum hexaboride filament, operated at an acceleration voltage of $200 \mathrm{kV}$. For its observation, the sample was mounted on a Formvar carbon-coated film 300 mesh gold grid. XEDS analyses were carried out with an Oxford Inca Energy TEM100 attachment. The XPS and Auger spectra were measured with a VG-Microtech Multilab 3000 electron spectrometer using a non-monochromatised $\mathrm{Mg}-K_{\alpha}(1253.6 \mathrm{eV})$ radiation source of $300 \mathrm{~W}$ and a hemispheric electron analyser equipped with 9 channeltron electron multipliers. The pressure inside the analysis chamber during the scans was about $5 \times 10^{-7} \mathrm{~N} \mathrm{~m}^{-2}$. After the survey spectra were obtained, higher resolution survey scans were performed at pass energy of $50 \mathrm{eV}$. The intensities of the different contributions were obtained by calculating the integral of each peak, after having eliminated the baseline with $\mathrm{S}$ form and adjusting the experimental curves to a combination of Lorentz (30\%) and Gaussian $(70 \%)$ lines. All the bond energies were referred to the line of the $\mathrm{C} 1 \mathrm{~s}$ to $284.4 \mathrm{eV}$, obtaining values with a precision of $\pm 0.2 \mathrm{eV}$.

Typical Procedure for the Preparation of $\mathrm{CuNPs} / \mathrm{TiO}_{2}$ : Anhydrous copper(II) chloride (135 mg, $1 \mathrm{mmol}$ ) was added to a suspension of lithium (14 mg, $2 \mathrm{mmol})$ and DTBB (27 mg, $0.1 \mathrm{mmol})$ in THF $(2 \mathrm{~mL})$ at room temperature under an argon atmosphere. The reaction mixture, which was initially dark-blue, rapidly changed to black, indicating that a suspension of copper nanoparticles was formed. This suspension was diluted with THF $(18 \mathrm{~mL})$ followed by the addition of $\mathrm{TiO}_{2}(1.28 \mathrm{~g})$. The resulting mixture was stirred for $1 \mathrm{~h}$ at room temperature, filtered, and the solid was washed with THF $(20 \mathrm{~mL})$ and dried under vacuum.

General Procedure for the Homocoupling of Alkynes Catalysed by CuNPs/TiO 2 : The alkyne $(\mathbf{1}, 1 \mathrm{mmol})$ and piperidine $(30 \mathrm{~mol}-\mathrm{o} \%)$ were added to a suspension of $\mathrm{CuNPs} / \mathrm{TiO}_{2}(20 \mathrm{mg}, 1 \mathrm{~mol}-\% \mathrm{Cu})$ either in THF $(2 \mathrm{~mL})$ or without solvent. The reaction mixture was warmed to $65^{\circ} \mathrm{C}$ without exclusion of air and monitored by TLC and/or GC until complete conversion of the starting material. Water $(30 \mathrm{~mL})$ was added to the resulting mixture followed by extraction with EtOAc $(3 \times 10 \mathrm{~mL})$. The collected organic phases were dried with anhydrous $\mathrm{MgSO}_{4}$ and the solvent was removed in 
vacuo to give the corresponding homocoupled products $\mathbf{2}$. All diynes $\mathbf{2 a},{ }^{[8]} \mathbf{2 b},{ }^{[8]} \mathbf{2 c},{ }^{[21]} \mathbf{2 d},{ }^{[22]} \mathbf{2 e},{ }^{[8]} \mathbf{2 f},{ }^{[23]} \mathbf{2 g},{ }^{[8]} \mathbf{2} \mathbf{h},{ }^{[24]} \mathbf{2} \mathbf{i},{ }^{[25]} \mathbf{2 j},{ }^{[8]} \mathbf{2 k},{ }^{[8]}$ $\mathbf{2 1},{ }^{[26]} \mathbf{2} \mathbf{m},{ }^{[27]} \mathbf{2 n},{ }^{[10]} \mathbf{2 0},{ }^{[28]}$ and $\mathbf{2} \mathbf{p}^{[29]}$ were characterised by comparison of their physical and spectroscopic data with those described in the literature.

\section{Acknowledgments}

This work was generously supported by the Spanish Ministerio de Ciencia e Innovación [(MICINN) (grant number CTQ2007-65218) and Consolider Ingenio (grant number 2010-CSD2007-00006)], the Generalitat Valenciana (grant no. PROMETEO/2009/039), and the Fondos Europeos para el Desarrollo Regional (FEDER). Y. M. thanks the Vicerrectorado de Investigación, Desarrollo e Innovación of the Universidad de Alicante for a grant. T. M. acknowledges the Erasmus Programme for a mobility grant. The authors are very grateful to Robison Buitrago (Departamento de Química Inorgánica, Universidad de Alicante) for performing the TPD experiment.

[1] For a review, see: R. R. Tykwinski, A. L. K. Shi Shun, Angew. Chem. 2006, 118, 1050-1073; Angew. Chem. Int. Ed. 2006, 45, 1034-1057.

[2] a) F. Diederich, P. J. Stang, R. R. Tykwinski, Acetylene Chemistry: Chemistry, Biology, and Materials Science, Wiley-VCH, Weinheim, Germany, 2005; b) J. Liu, J. W. Y. Lam, B. Z. Tang, Chem. Rev. 2009, 109, 5799-5867.

[3] For reviews, see: a) P. Siemsen, R. C. Livingston, F. Diederich, Angew. Chem. 2000, 112, 2762-2789; Angew. Chem. Int. Ed. 2000, 39, 2632-2657; b) H. A. Stefani, A. S. Guarezemini, R. Cella, Tetrahedron 2010, 66, 7871-7918.

[4] a) C. Glaser, Ber. Dtsch. Chem. Ges. 1869, 2, 422-424; b) C. Glaser, Ann. Chem. Pharm. 1870, 154, 137-171; c) L. Brandsma, Synthesis of Acetylenes, Allenes and Cumulenes, Elsevier Academic Press, Amsterdam, 2004, chapter 15.

[5] For very recent contributions, see: a) Q. Zheng, R. Hua, Y. Wan, Appl. Organomet. Chem. 2010, 24, 314-316; b) D. Wang, J. Li, N. Li, T. Gao, S. Hou, B. Chen, Green Chem. 2010, 12, 45-48; c) X. Meng, C. Li, B. Han, T. Wang, B. Chen, Tetrahedron 2010, 66, 4029-4031; d) K. Balaraman, V. Kesavan, Synthesis 2010, 3461-3466.

[6] a) Supported Metals in Catalysis (Eds.: J. A. Anderson, M. Fernández García), Imperial College Press, London, 2005; for a review, see: b) K. Kaneda, K. Ebitani, T. Mizugaki, K. Mori, Bull. Chem. Soc. Jpn. 2006, 79, 981-1016.

[7] B. C. Zhu, X. Z. Jiang, Appl. Organomet. Chem. 2007, 21, 345349.
[8] P. Kuhn, A. Alix, M. Kumarraja, B. Louis, P. Pale, J. Sommer, Eur. J. Org. Chem. 2009, 423-429.

[9] T. Oishi, T. Katayama, K. Yamaguchi, N. Mizuno, Chem. Eur. J. 2009, 15, 7539-7542.

[10] F. Nador, L. Fortunato, Y. Moglie, C. Vitale, G. Radivoy, Synthesis 2009, 4027-4031.

[11] For reviews, see: a) F. Alonso, G. Radivoy, M. Yus, Russ. Chem. Bull. Int. Ed. 2003, 52, 2563-2576; b) F. Alonso, M. Yus, Chem. Soc. Rev. 2004, 33, 284-293; c) F. Alonso, M. Yus, Pure Appl. Chem. 2008, 80, 1005-1012.

[12] a) F. Alonso, C. Vitale, G. Radivoy, M. Yus, Synthesis 2003, 443-447; b) F. Alonso, Y. Moglie, G. Radivoy, C. Vitale, M. Yus, Appl. Catal. A: Gen. 2004, 271, 171-176; c) G. Radivoy, F. Alonso, Y. Moglie, C. Vitale, M. Yus, Tetrahedron 2005, 61, 3859-3864.

[13] a) F. Alonso, Y. Moglie, G. Radivoy, M. Yus, Tetrahedron Lett. 2009, 50, 2358-2362; b) F. Alonso, Y. Moglie, G. Radivoy, M. Yus, Eur. J. Org. Chem. 2010, 1875-1884.

[14] F. Alonso, Y. Moglie, G. Radivoy, M. Yus, Adv. Synth. Catal. 2010, 352, 3208-3214.

[15] H.-X. Zhang, U. Siegert, R. Liu, W.-B. Cai, Nanoscale Res. Lett. 2009, 4, 705-708.

[16] J. J. Brege, C. E. Hamilton, C. A. Crouse, A. R. Barron, Nano Lett. 2009, 9, 2239-2242.

[17] L. Huang, F. Peng, H. Wang, H. Yu, Z. Li, Catal. Commun. 2009, 10, 1839-1843.

[18] NIST X-ray Photoelectron Spectroscopy Database, http://srdata.nist.gov/xps/.

[19] Practical Surface Analysis by Auger and X-ray Photoelectron Spectroscopy (Eds.: D. Briggs, M. P. Seach), John Wiley \& Sons, New York, 1983.

[20] A. A. Clifford, W. A. Waters, J. Chem. Soc. 1963, 3056-3062.

[21] S. Chassaing, A. Alix, T. Boningari, K. S. S. Sido, M. Keller, P. Kuhn, B. Louis, J. Sommer, P. Pale, Synthesis 2010, 15571567.

[22] C. Koradin, W. Dohle, A. L. Rodriguez, B. Schmid, P. Knochel, Tetrahedron 2003, 59, 1571-1587.

[23] S. Adimurthy, C. C. Malakar, U. Beifuss, J. Org. Chem. 2009, $74,5648-5651$.

[24] A. Coste, F. Couty, G. Evano, Synthesis 2010, 1500-1504.

[25] A. Lei, M. Srivastava, X. Zhang, J. Org. Chem. 2002, 67, 19691971.

[26] K. Kamata, S. Yamaguchi, M. Kotani, K. Yamaguchi, N. Mizuno, Angew. Chem. 2008, 120, 2441-2444; Angew. Chem. Int. Ed. 2008, 47, 2407-2410.

[27] T. Kurita, M. Abe, T. Maegawa, Y. Monguchi, H. Sajiki, Synlett 2007, 2521-2524.

[28] H. Jiang, W. Wang, B. Yin, W. Liu, Eur. J. Org. Chem. 2010, 4450-4453.

[29] H.-F. Jiang, J.-Y. Tang, A.-Z. Wang, G.-H. Deng, S.-R. Yang, Synthesis 2006, 1155-1161.

Received: December 28, 2010 Published Online: 
The homocoupling of terminal alkynes catalysed by ultrafine copper nanoparticles on titania is described. The methodology is very simple and applicable to a wide range of alkynes, furnishing the corresponding 1,3-diynes in high yields. The catalyst is reusable and exhibited better performance than commercially available copper catalysts, working even under an inert atmosphere.

$\mathrm{R}=\frac{\begin{array}{l}1 \mathrm{~mol}-\% \text { CuNPs} / \mathrm{TiO}_{2} \\ 30 \mathrm{~mol}-\% \text { piperidine }\end{array}}{\begin{array}{l}\mathrm{THF} \text { or solventless } \\ 65^{\circ} \mathrm{C}, 2-24 \mathrm{~h}\end{array}} \mathrm{R}-\mathrm{R}$

\section{F. Alonso,* T. Melkonian, Y. Moglie,}

M. Yus*

1-8

Homocoupling of Terminal Alkynes Catalysed by Ultrafine Copper Nanoparticles on Titania

Keywords: Alkynes / C-C coupling / Copper / Nanoparticles / Titanium / Heterogeneous catalysis 